\section{(6) OPEN ACCESS}

\title{
Symptomatic reflux disease: the present, the past and the future
}

\author{
Guy Boeckxstaens, ${ }^{1}$ Hashem B El-Serag, ${ }^{2}$ André J P M Smout, ${ }^{3}$ Peter J Kahrilas ${ }^{4}$
}

\begin{abstract}
${ }^{1}$ Department of
Gastroenterology, Translational

Research Center for Gastrointestinal Disorders (TARGID), University Hospital Leuven, KU Leuven, Leuven, Belgium

${ }^{2}$ Section of Gastroenterology and Hepatology, Baylor College of Medicine, Houston, Texas, USA

${ }^{3}$ Department of

Gastroenterology and

Hepatology, Academic Medical Centre, Amsterdam, The Netherlands

${ }^{4}$ Division of Gastroenterology and Hepatology, Department of Medicine, Northwestern University Feinberg School of Medicine, Chicago, Illinois, USA
\end{abstract}

\section{Correspondence to} Dr Peter J Kahrilas, Division of Gastroenterology and Hepatology, Department of Medicine, Northwestern University, Feinberg School of Medicine, 676 N. St. Clair Street, 14th Floor, Chicago, IL 60611, USA;

p-kahrilas@northwestern.edu

Received 20 January 2014 Accepted 1 February 2014 Published Online First

7 March 2014

This is a reprint of a paper that first appeared in Gut, 2014, Volume 63, pages 11851193.

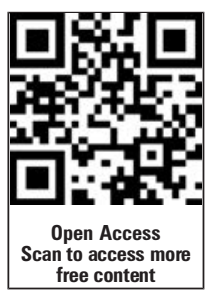

\section{CrossMark}

To cite: Boeckxstaens $G$ El-Serag HB, Smout AJPM, et al. Gut 2014;63: 1185-1193.

\section{ABSTRACT}

The worldwide incidence of GORD and its complications is increasing along with the exponentially increasing problem of obesity. Of particular concern is the relationship between central adiposity and GORD complications, including oesophageal adenocarcinoma. Driven by progressive insight into the epidemiology and pathophysiology of GORD, the earlier belief that increased gastroesophageal reflux mainly results from one dominant mechanism has been replaced by acceptance that GORD is multifactorial. Instigating factors, such as obesity, age, genetics, pregnancy and trauma may all contribute to mechanical impairment of the oesophagogastric junction resulting in pathological reflux and accompanying syndromes. Progression of the disease by exacerbating and perpetuating factors such as obesity, neuromuscular dysfunction and oesophageal fibrosis ultimately lead to development of an overt hiatal hernia. The latter is now accepted as a central player, impacting on most mechanisms underlying gastroesophageal reflux (low sphincter pressure, transient lower oesophageal sphincter relaxation, oesophageal clearance and acid pocket position), explaining its association with more severe disease and mucosal damage. Since the introduction of proton pump inhibitors (PPI), clinical management of GORD has markedly changed, shifting the therapeutic challenge from mucosal healing to reduction of PPI-resistant symptoms. In parallel, it became clear that reflux symptoms may result from weakly acidic or non-acid reflux, insight that has triggered the search for new compounds or minimally invasive procedures to reduce all types of reflux. In summary, our view on GORD has evolved enormously compared to that of the past, and without doubt will impact on how to deal with GORD in the future.

\section{INTRODUCTION}

Over the past 40 years, reflux disease has risen from relative obscurity to one of the dominant clinical problems encountered in Gastroenterology. First evident in Western societies, this trend is now extending worldwide. However, the underlying explanations for this development are only slowly emerging. Indeed, our understanding of the pathogenesis, clinical spectrum and epidemiology of GORD has continuously evolved. At first, reflux was synonymous with oesophagitis and hiatus hernia. Then, it was a motility disorder, defined by sphincter or peristaltic dysfunction. Next, it was an acid-peptic disorder. Now, we see GORD emerging as a heterogeneous entity encompassing elements of all these concepts. Each phase of the conceptualisation of GORD was championed by a key development in diagnostics or therapeutics. Barium contrast radiography defined the sliding hiatus hernia and first visualised reflux. Manometry and its subsequent refinements first verified the existence of the previously elusive lower oesophageal sphincter (LOS) and then demonstrated its dynamic function. Endoscopy refined the grading of erosive oesophagitis (EO). Ambulatory oesophageal $\mathrm{pH}$ monitoring quantified non-erosive reflux disease. Impedance monitoring expanded on $\mathrm{pH}$-metry with detection of reflux of liquid and gas irrespective of acidity. However, a major development that morphed our understanding of GORD was the development and widespread clinical use of proton pump inhibitors (PPI). So effective were PPIs in treating GORD that enthusiasts in the clinical community proposed that GORD be defined by response (or failure of response) to PPI therapy. ${ }^{1}$ Fortunately, that sentiment has since receded and the ultimate lesson from PPI therapy was in the limitations of their clinical usefulness. Yet another over-simplification and a good time to reflect on the current status of GORD: its definition, epidemiology, pathogenesis and management.

\section{WHAT IS GORD?}

Parallel with the introduction of PPIs came an improved understanding of the full clinical spectrum of GORD. Whereas in the past, clinicians had struggled to manage reflux oesophagitis, ulcers and recurrent strictures with antacids and histamine-2 receptor antagonists, these problems quickly succumbed to the potent acid suppression made possible with PPIs. In fact, with rare exception, it became widely accepted that the mucosal manifestations of GORD (other than Barrett's metaplasia) can be controlled indefinitely with sustained PPI therapy. ${ }^{2}$ However, as the problem of refractory mucosal disease receded, the problem of refractory symptoms blossomed and the list of symptoms and syndromes potentially attributable to GORD expanded. These developments prompted the formation of an international consensus conference, ultimately resulting in the 'Montreal definition' of GORD. The proposed overarching definition of GORD was 'a condition which develops when the reflux of stomach contents causes troublesome symptoms and/or complications. ${ }^{3}$

The Montreal definition was evolutionary in that there had really been no prior attempt at developing a unifying concept of what constituted GORD. Neither the clinical spectrum of the disorder(s) nor the defining features of the 'disease' had ever been clearly articulated. The consensus document went on to explore the relationships between erosive and non-erosive disease, oesophageal and extraoesophageal manifestations, and to review 
health-related quality-of-life data pertinent to reflux symptoms in order to define the term 'troublesome'. With regard to the latter, no threshold values for symptom severity could be proposed for any potential reflux symptoms other than heartburn, because no relevant data could be found in the literature. Subsequently, a threshold for severity has also been developed for the symptom of regurgitation based on analysis of an extensive quality-of-life dataset. ${ }^{4}$ Nonetheless, the concept of 'refractory GORD' shifted from one of persistent mucosal disease to one of potential GORD symptoms not eliminated with PPI therapy. ${ }^{5}$ Not surprisingly, the other development that ensued with adoption of the Montreal definition of GORD was that potential GORD symptoms refractory to acid-suppressive therapy emerged as one of the most common reasons for gastroenterological consultations in the USA and western Europe.

\section{GORD EPIDEMIOLOGY AND SOME FASCINATING TRENDS BEHIND THAT EPIDEMIOLOGY}

The global burden of GORD is increasing; data from 28 studies of GORD prevalence (defined by either typical symptoms at least once weekly or the Montreal definition) indicate estimates of 18.1-27.8\% in North America, 8.8-25.9\% in Europe, 2.5$7.8 \%$ in East Asia, 8.7-33.1\% in the Middle East, $11.6 \%$ in Australia, and 23.0\% in South America. Furthermore, the prevalence of GORD is $\approx 50 \%$ higher in the USA, Europe and East Asia in studies carried out after 1995 compared to those carried out before 1995. The incidence of GORD per 1000 personyears is approximately 5.0 in the overall UK and US populations, and 0.84 in UK paediatric patients aged $1-17$ years. ${ }^{6}$

The incidence and mortality rates of oesophageal adenocarcinoma (OAC) have also been increasing in regions of North America, Europe and Australia. The risk of OAC increases with age, peaking at the 7 th-8th decade of life. However, people born in more recent years have a higher incidence of OAC, independent of age. ${ }^{7}$ This birth cohort phenomenon implicates an early life exposure that increased the risk of OAC in successive generations. ${ }^{8}$

There are remarkable variations in the distribution of GORD-related disorders (reflux symptoms, EO, Barrett's oesophagus (BO), and $\mathrm{OAC}$ ) related to sex, race and geographic regions (figure 1). Similar proportions of men and women report GORD symptoms, but increasingly greater proportions of men than women are affected with EO $(\approx 60 \%)$, BO $(\approx 70 \%)$, and OAC $(\approx 80 \%)$. Similarly, the prevalence of EO, BO and $\mathrm{OAC}$ are remarkably low in endoscopic series from East Asia (figure 2). Lastly, within some regions, there exist racial and ethnic variations exemplified by differences between whites and blacks in the USA, such that GORD symptoms are similar between the two groups, but whites are disproportionately affected with EO (60\%), BO ( $\approx 70 \%)$ and OAC (fivefold higher incidence among whites than blacks). ${ }^{9}$

\section{Stories behind the trends}

Rising rates of obesity together with declining rates of Helicobacter pylori infection are likely behind the observed increase in early onset GORD. The result is a larger number of people living with chronic GORD and, thus, at high risk for developing $\mathrm{BO}$ and OAC. The increasing prevalence of abdominal obesity also independently increases the risk of BO and OAC. These factors underlie some of the observed geographic, gender and racial differences.

Obesity is associated with a significant increase in the risk for GORD. However, waist circumference and waist-to-hip ratio have been shown to correlate more strongly than BMI with the

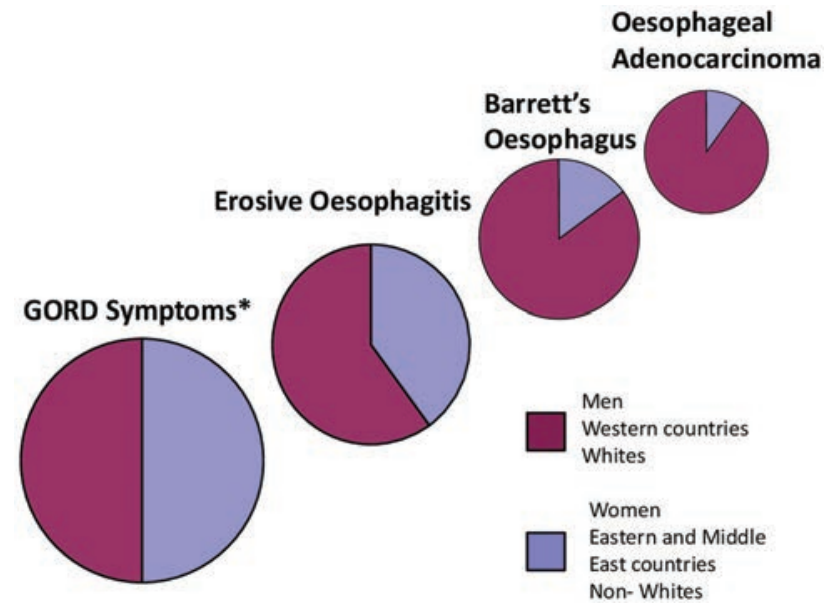

Figure 1 Schematic presentation of epidemiological trends in GORD-related disorders. While typical GERD symptoms are balanced between comparator groups, the distribution of complications becomes progressively skewed in gender, geographic and racial distribution. ${ }^{*}$ GORD symptoms are similar between Western and Middle Eastern countries, but are lower in Eastern countries.

risk of $\mathrm{EO}, \mathrm{BO}^{10}$ and $\mathrm{OAC}$. In a recent meta-analysis, patients with central adiposity had a higher risk of EO (19 studies; OR, 1.87 ; $95 \%$ CI 1.51 to 2.31 ), BO (17 studies; OR, 1.98 ; $95 \% \mathrm{CI}$ 1.52 to 2.57$)$ and OAC (OR, $2.51 ; 95 \%$ CI 1.54 to 4.06$)$ compared with subjects of normal body habitus and the association between central adiposity and $\mathrm{BO}$ persisted after adjusting for BMI (5 studies; OR, 1.88; 95\% CI 1.20 to 2.95). Furthermore, a reflux-independent association of central adiposity and $\mathrm{BO}$ was observed in studies that used GORD patients as controls or adjusted for GORD symptoms (11 studies; OR, 2.04; 95\% CI 1.44 to 2.90$).{ }^{11}$ These findings support a role for central adiposity, independent of $\mathrm{BMI}$ in increasing the risk of $\mathrm{BO}$ and $\mathrm{OAC}$ with its effects mediated by reflux-dependent and refluxindependent mechanisms. ${ }^{12}$

Abdominal obesity promotes GORD by elevating intra-abdominal pressure, which promotes reflux and the development of hiatus hernia. ${ }^{13}$ Studies comparing computerised tomography-measured abdominal fat composition showed that patients with $\mathrm{EO}, \mathrm{BO}$ and $\mathrm{OAC}$ had greater intra-abdominal visceral adiposity than controls. ${ }^{14}$ The metabolically active visceral abdominal fat may also predispose to $\mathrm{BO}$ and $\mathrm{OAC}$ by GORD-independent mechanisms that promote the progression from inflammation to metaplasia and neoplasia; these include alterations in the levels of adipokines, cytokines and chemokines, as well as the insulin/insulin growth factor pathways. ${ }^{15}$ Obesity, especially abdominal obesity, may also explain some of the epidemiological trends in GORD-related disorders: obesity is increasing in most regions affected by the increase in GORD; obesity is more common in men than women; and abdominal obesity is more likely in men than women (apple vs pear-shaped body habitus) and in Caucasians than in blacks. ${ }^{16}$

Childhood GORD is also rising and it predisposes to chronic GORD. Long-duration GORD symptoms, especially with high frequency and severity or EO, ${ }^{17}$ are strongly associated with an increased risk of BO and OAC. Between 2000 and 2005, the annual incidence of GORD among infants in the USA more than tripled (from $3.4 \%$ to $12.3 \%$ ), and increased by $30-50 \%$ for children and adolescents. ${ }^{18}$ A large proportion (40-50\%) of otherwise normal children with GORD have GORD symptoms that require treatment for an average of 10 years after 
Figure 2 Age-adjusted incidence rates of oesophageal adenocarcinoma for men and women in 1998-2002 in several regions. Reference population is world standard population (2000).

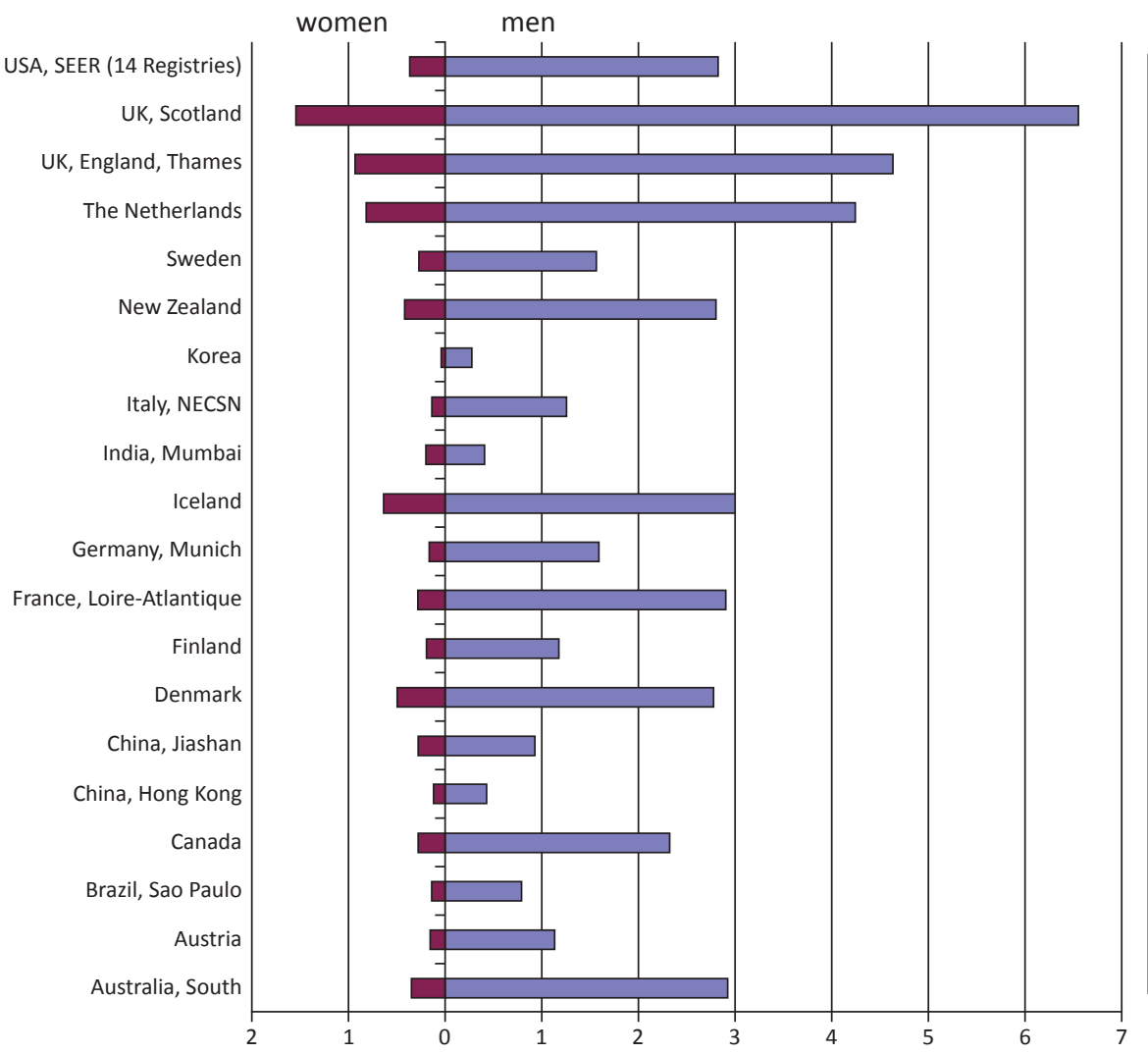

diagnosis. ${ }^{19} 20$ Even though $\mathrm{BO}$ and OAC are rare in the first 3-4 decades of life, age of $<30$ years at onset of frequent (at least weekly) GORD symptoms was associated with the highest risk of $\mathrm{BO}(\mathrm{OR}=15.1,95 \% \mathrm{CI} 7.91$ to 28.8$)$, and the risk increased linearly with younger age at onset; an association that was independent of cumulative symptom duration. ${ }^{21}$

Coincident with the increase in GORD (and OAC), PPI use has increased dramatically during the past two decades. With some support from animal studies, this has led to the hypothesis that PPIs may actually promote the development of BO and OAC. However, in meta-analysis of seven observational studies with 2813 patients with BO, PPI use was associated with a $71 \%$ reduction in risk of $\mathrm{OAC}$ and/or $\mathrm{BO}$ with high-grade dysplasia in patients with BO (adjusted OR 0.29; 95\% CI 0.12 to 0.79 ) OAC. ${ }^{22}$ None of these studies show an increased risk of OAC with PPI use, making it highly unlikely that PPI use is an explanation for the observed epidemiological trends in OAC.

While there has been no consistent association between the presence or treatment of $H$ pylori and GORD symptoms, pooled data suggest $H$ pylori as a possible preventive factor for EO, BO and OAC. A meta-analysis of 49 studies demonstrated that $H$ pylori, especially cag-A strains, tended to be protective for BO. ${ }^{23}$ Similarly, a meta-analysis of 13 studies that examined the association between $\mathrm{OAC}$ and $H$ pylori reported a summary OR for $H$ pylori in OAC of 0.56 (95\% CI 0.46 to 0.68), and an even lower OR for cag-A strains of 0.41 (95\% CI 0.28 to $0.62)^{24}$; more recent studies confirmed this finding. ${ }^{25}$ This effect is postulated to be attributable to decreased acid production resulting from corpus gastritis or gastric atrophy, leading to decreased oesophageal exposure to acid and, thus, a decrease in risk of $\mathrm{BO}$ and OAC. ${ }^{26} 27 \mathrm{H}$ pylori infection also offers a partial explanation for the observed trends in GORD epidemiology; the infection is very common in regions with low BO and OAC, and among racial groups (eg, blacks) less likely to develop these conditions. However, there is no evidence that $H$ pylori or the associated gastritis is different between men and women.

\section{THEORIES OF GORD PATHOGENESIS}

Although the symptom of heartburn (pyrosis) was described long ago, ${ }^{28}$ the modern history of reflux disease began with the description of peptic oesophagitis in 1935 by Asher Winkelstein $^{29}$ and it was not really until after the pharmacological control of peptic ulcer disease with the $\mathrm{H}_{2}$-receptor antagonists and the discovery of $H$ pylori that reflux disease emerged as the dominant acid-peptic disorder among Western societies. And in the short window of time since then, our understanding of the GORD pathophysiology has continuously evolved, some might even say revolved, with perpetual oversimplifications. From the beginning, it was evident that GORD was multifactorial, but after stating that, there was a persistent tendency among clinicians to explain GORD in one-dimensional concepts. First it equated to the hernia, then to the LOS, then to transient LOS relaxations (TLOSRs). Only now have we begun to understand how these elements of GORD pathogenesis all interact, truly making this a multifactorial disease.

Before, there were ways to pharmacologically control acid secretion, the therapeutic options for severe reflux were few, largely restricted to surgery. Philip Allison, Norman Barrett, Rudolph Nissen, Ronald Belsey, Lucius Hill and Marco Rossetti were the pioneers of that practice, progressively refining techniques for antireflux surgery. ${ }^{30}$ The issue was not whether or not to repair the hiatal hernia, but how to best achieve that. However, somewhat lost in this bit of history were the numbers; in the landmark publication on the 5-year experience with his technique of hernia repair, Allison reported on only 33 patients. $^{30}$ However, the same critique pertains to the 
monumental 1971 publication that subsequently dethroned hiatus hernia as the cause of GORD: 'symptomatic patients $(n=37)$ were readily separated from asymptomatic ones $(n=38)$ by a weaker base-line sphincter strength and by decreased sphincteric response to an increased intra-abdominal pressure. However, in neither the asymptomatic nor the symptomatic groups of patients could any effect of hiatus hernia be found. ${ }^{31}$, In each case, basic tenets of GORD pathogenesis were based on studies of fewer than 100 patients.

Much has changed since 1971. Key developments in our thinking on GORD pathogenesis were: (1) the conceptualisation of the oesophagogastric junction (OGJ) as a complex sphincter comprised of the LOS and the surrounding crural diaphragm (CD) with the CD being dominant in preventing strain-induced reflux events ${ }^{32} 33$; (2) the demonstration that TLOSRs rather than LOS hypotension were the dominant mechanism of LOS dysfunction leading to gastroesophageal reflux events ${ }^{34-36}$; (3) the realisation that prolonged acid clearance from the oesophagus rather than an excessive number of reflux events was the most dominant factor in the development of oesophagitis and its sequelae ${ }^{36-38}$; (4) the demonstration that increased OGJ compliance in symptomatic GORD patients results in greater reflux volumes per event, more proximal spread of reflux within the oesophagus, a reduced ability to restrict reflux to gas (belching), and an increased probability of a reflux event being symptomatic ${ }^{39-42}$; (5) 're-discovery' of the postprandial acid pocket that forms as the consequence of pooling of newly secreted acid in the proximal stomach above ingested chyme with which it mixes very little $e^{43-47}$; (6) recognition that acid reflux in the immediate postprandial period originates from this acid pocket $^{4446}{ }^{47}$; (7) increased focus on the role of the longitudinal layer of the oesophageal muscularis propria in effecting LOS opening, and eliciting reflux symptoms, ${ }^{48} 49$ and, most fundamental, (8) the demonstration that hiatus hernia directly affects and/or exacerbates all the aforementioned factors. ${ }^{46} 50-53$

Thus, the hiatus hernia was resurrected as a major component of GORD pathogenesis, albeit with more restraint and in a more mechanistic construct. Figure 3 diagrams an attempt at modelling the interaction of pathogenetic factors leading to the major manifestations of GORD. Note that the construct of mechanical degradation of the OGJ is conceptualised as a continuum beginning with subtle functional alterations and ending with overt hernia. A conglomerate of forces nudges this continuum along, most likely dominated by age-related change and abdominal obesity. In the intermediate condition, between normal and overt hernia, the demonstration of hiatus hernia can be intermittent, ${ }^{54}$ with dysfunction exacerbated by increased abdominal girth ${ }^{55}$ and even simple behaviours such as belt tightening. ${ }^{56}$ The operant mechanism through which the abdominal obesity effect is mediated is likely the proportional increase in intra-abdominal pressure, which challenges the anatomical integrity of this delicately constructed valve, and also serves as the pressure head driving the retrograde flow of gastric content. ${ }^{57}$ However, once established, the very nature of these disease determinants makes them disease perpetuating. More often than not, GORD is a chronic disease.

Notably absent from figure 3 is any mention of abnormal gastric acid secretion. This is quite a paradox considering that acid suppression has become the mainstay of GORD therapy; it also goes a long way to explaining the observed limitations of acid suppressive therapy in treating the multitude of potential manifestations of GORD. As the focus of the disease process migrates away from the distal oesophageal epithelium, the dominance of acid as a major pathophysiological determinant diminishes. Indeed, with syndromes, such as reflux-induced cough, it is becoming increasingly evident that visceral hypersensitivity of the oesophagus ${ }^{58}$ and the airways play the dominant role. ${ }^{59}$

\section{MANAGEMENT OF SYMPTOMATIC REFLUX}

A few decades ago, when GORD equated only to oesophagitis, healing of the mucosal lesions was the treatment goal. With the advent of PPIs in the late 1980s, this goal was easily achieved. In most parts of the world, that led to a marked decline in the perceived need for other treatment modalities, such as surgical fundoplication. However, as our understanding of GORD evolved, awareness grew that persistent reflux symptoms or symptoms occurring in the absence of oesophagitis constituted the majority of management problems. The therapeutic implications of these observations are summarised in figure 4 comparing the efficacy of PPIs in treating esophagitis to their efficacy in treating potential GORD syndromes other than oesophagitis. ${ }^{60}$
Figure 3 Model of GORD pathogenesis, conceptualising the progressive development of reflux manifestations with the progressive degradation of physiological defence mechanisms. With the accumulation of these 'hits' physiological reflux in transformed into pathological reflux manifest either symptomatically and/or with mucosal disease. Abdominal obesity plays a dominant role with its effect mediated through progressive degradation of the oesophagogastric junction (OGJ) culminating in the development of overt hiatus hernia.

\section{Model of GORD Pathogenesis in Adults}

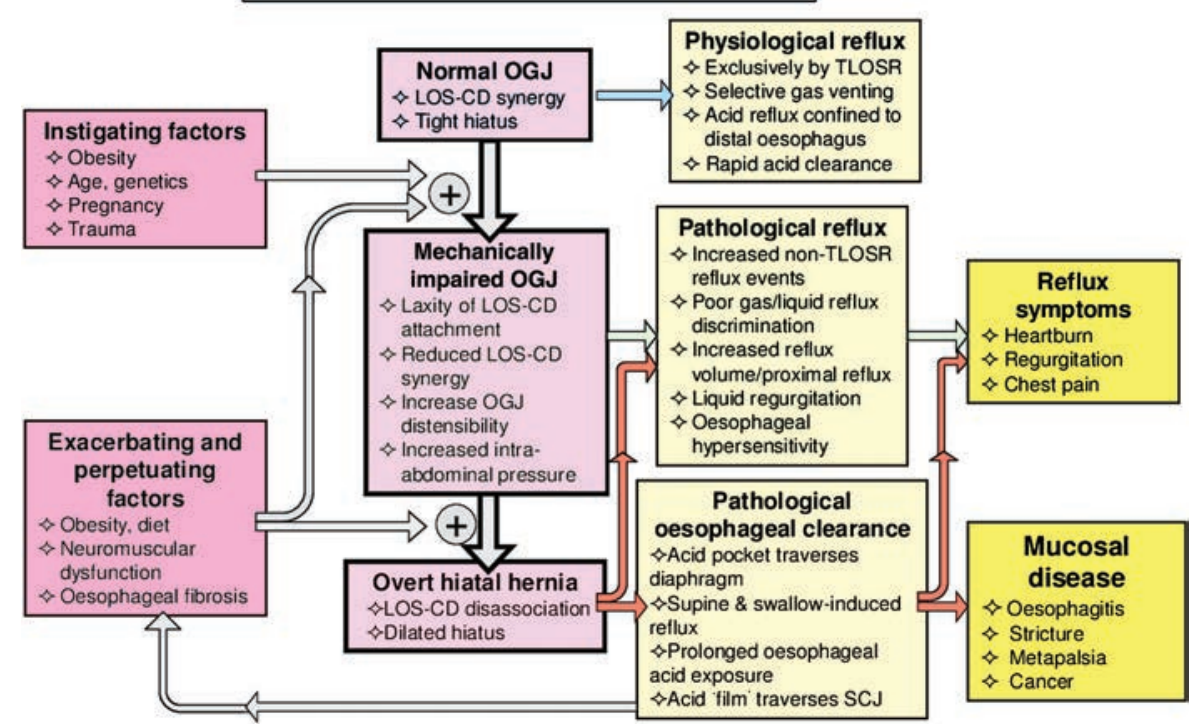


Figure 4 Summary of proton pump inhibitor (PPI) efficacy for various GERD syndromes as assessed in randomised controlled trials. In each case, data among trials are averaged to derive estimates of placebo effect and therapeutic gain, defined as the degree to which PPI therapy improved upon the benefit seen with placebo. The blue segments represent the placebo effect and the green arrows the therapeutic gain beyond the placebo effect seen with PPIs. PPI data are grouped in terms of brand and dose, taking some liberties for simplification. However, it is imperative to recognise that the only disease manifestation in which a dose-response curve has been convincingly demonstrated by randomised controlled trial is in healing esophagitis. At the other extreme, in the case of asthma, controlled trial data are sparse and largest trial, in fact, showed the placebo response to be insignificantly better that the PPI. ${ }^{66}$ Modified from Kahrilas et al 2012. ${ }^{60}$

\section{PPI efficacy for potential manifestations of GERD Estimates based on available RCT data}

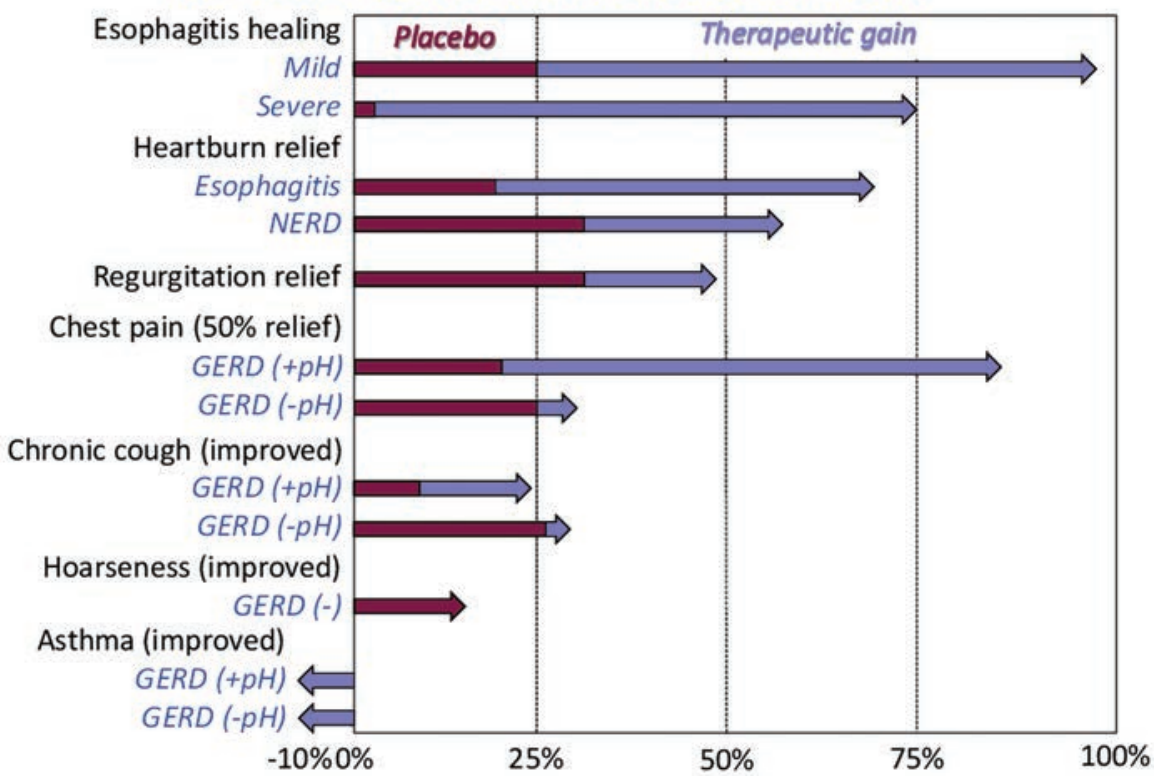

Evident in the figure, PPI efficacy diminishes progressively moving from oesophagitis to symptomatic heartburn, regurgitation, ${ }^{61}{ }^{62}$ chest pain, ${ }^{63}$ cough, ${ }^{64}$ laryngitis ${ }^{65}$ and asthma. ${ }^{66}$ Improving these therapeutic outcomes hinges upon finding alternative treatment strategies that are either more efficacious in preventing reflux or in treating disease cofactors that are often equally important with these conditions. The demonstration that non-acid, or weakly acidic, reflux can also evoke symptoms (including heartburn) further contributed to a search for other ways of treating symptomatic GORD. ${ }^{67}$

\section{Lifestyle modification and weight reduction}

Whereas it is generally recommended to advise lifestyle changes, the evidence for efficacy of these recommendations in GORD management is mostly anecdotal. It therefore seems wise to limit these recommendations to a generally healthy diet and avoidance of (or moderation with) specific food items or activities that, in the experience of the patient, evoke symptoms. A much more relevant general focus is on weight control. A multitude of studies demonstrated a correlation between obesity and GORD and, as illustrated in figure 3, obesity, especially of the abdomen, is increasingly invoked in theories of pathogenesis. There is also evidence for the efficacy of weight reduction in reducing GORD symptoms. ${ }^{68} 69$ One of these studies reported that a decrease in BMI as little as $3.5 \mathrm{~kg} / \mathrm{m}^{2}$ leads to a nearly $40 \%$ risk reduction of GORD, even among women with a normal BMI. ${ }^{68}$ Hence, although the published evidence that weight loss leads to reduced reflux may not be abundant, it is sufficient to warrant recommending weight reduction as an important weapon in the battle against the GORD epidemic. Furthermore, in patients being considered for bariatric surgery, it is important to be aware of the differential effects of the various options on reflux. Gastric banding procedures generally decrease the prevalence of reflux symptoms (from 33\% to $8 \%$ ) but lead to de novo reflux symptoms in $23 \%$ of patients and to de novo oesophagitis in $23 \% .^{70}$ Likewise, the gastric sleeve resection increases the prevalence of oesophagitis from $18 \%$ to $45 \% .^{71}$ The only bariatric procedure that reduces reflux and reflux symptoms is the gastric bypass procedure with Roux-en-Y reconstruction. ${ }^{72}$ Some practitioners go as far as to recommend this procedure for the treatment of GORD in morbidly obese patients.

\section{Reduction of gastric acidity}

Although the pathogenesis of GORD is multifactorial, with the exception of extremely rare diseases associated with acid hypersecretion (eg, Zollinger-Ellison syndrome) the level of acid secretion in GORD patients is similar to that in asymptomatic controls. ${ }^{73}$ Nevertheless, the most widely practised management strategy for symptomatic GORD is reducing gastric acidity. Within that spectrum, antacids are mostly used for mild symptoms; their onset of action is rapid, but their effect short lived. Alternatively, histamine-2 receptor antagonists can be used for on-demand symptomatic treatment. ${ }^{74}$ However, in patients with moderate to severe symptoms, PPIs have become first-line therapy. $^{2}$ In general, the differences between available PPIs (esomeprazole, dexlansoprazole, lansoprazole, omeprazole, pantoprazole, rabeprazole) are small. However, patients with an insufficient therapeutic response to the standard dose of one PPI may benefit from one of the other PPIs, an increased dose of the same PPI, or a twice-a-day PPI regimen. ${ }^{2} 75$ The addition of a $\mathrm{H} 2$ blocker at bedtime to twice-daily PPI therapy also provides enhanced inhibition of nocturnal acid secretion, but this effect has not been shown clinically relevant and is subject to tachyphylaxis within a few weeks. ${ }^{76}$

\section{Insufficient symptomatic response to acid inhibition}

Evident in figure 4, the treatment success for potential GORD symptoms by reducing gastric acidity is variable. With our current insight, this should not be surprising. First, excessive gastric acid secretion is not a major factor in GORD pathogenesis. Second, a substantial proportion of symptom-provoking reflux episodes are not caused by acid reflux. ${ }^{67}$ However, largely as an unintended consequence of the Montreal definition, there is a third important cause of 'PPI failure' in symptomatic GORD; an incorrect diagnosis. No symptom is absolutely specific for GORD, not even heartburn. Hence, if PPI treatment fails it is wise to reconsider the diagnosis. There lies the main 
use of reflux testing in disease management. Among the available tests, only the technique of combined intraluminal $\mathrm{pH}$-impedance monitoring detects all types of reflux (acid and weakly acidic, liquid and gaseous) and characterises the $\mathrm{pH}$ of the refluxate making it the most robust option. ${ }^{77}$ Although there are opposing views on how best to perform $\mathrm{pH}$-impedance monitoring in the refractory patients, the chance of establishing correlation between the reflux symptoms and reflux events is greatest when the patient is studied 'off' acid inhibitors. ${ }^{78}$ When only $\mathrm{pH}$ is recorded, discontinuation of PPI treatment is obligatory. Two-day $\mathrm{pH}$ recording using the radiocapsule technique (Bravo) is associated with a higher chance of finding a positive symptom association than 24 -h recording. ${ }^{79}$

Using oesophageal $\mathrm{pH}$-impedance monitoring, four phenotypes of poorly responsive patients can be identified, each with unique management considerations (figure 5). Most easily dealt with are patients of phenotype 4 in whom a diagnosis of GORD can be excluded making antireflux therapy of little, if any, use. More complex are patients of phenotype 3, who have excessive reflux, but in whom a temporal association between symptoms and reflux episodes is not apparent. Technically, these patients have GORD, but treatment of GORD may or may not improve their persistent symptoms. Patients with pulmonary and otolaryngology syndromes typify this phenotype which can be particularly vexing in view of the absence of any high-level evidence for the effectiveness of any antireflux therapy. Phenotype 2 patients can also be quite challenging as they have physiological evidence of GORD, but it is complicated by oesophageal hypersensitivity, diminishing the efficacy of conventional therapy. Again, there is no high-level evidence in managing this population, but anecdotal and mechanistic data support the addition of perception modulators. More straightforward are phenotype 1 patients who have physiological evidence of GORD, manifest by excessive reflux and a positive symptom association. These patients should benefit from alternative antireflux therapy, be that pharmacological or surgical.

One of the ironies illustrated in figure 5 is that in the analysis of 'PPI failures', it is actually quite rare for PPIs to have failed.
Although it can occur by genetic variations in the proton pump, total lack of effect of PPIs on acid secretion is extremely rare. ${ }^{80}$ On the other hand, non-compliance is not; studies have shown that $25 \%-47 \%$ of the patients with GORD exhibit moderate to poor compliance (less than $80 \%$ intake of prescribed dose of PPI ${ }^{81}$ making this an important management possibility to pursue.

\section{Medicinal options other than acid inhibition}

The disconnect between GORD pathogenesis detailed in figure 3 and treatment strategies targeting acid secretion has prompted a search for a more 'physiological' approach. Theoretically, treatment with a prokinetic drug that accelerated gastric emptying, increased LOS pressure or improved clearance of the refluxate from the oesophagus would be beneficial. However, that approach, exemplified by metoclopramide, domperidone and cisapride has been only marginally successful, hampered by limited efficacy and/or recalcitrant safety issues. An alternative motility strategy was to target TLOSRs, and enthusiasm for that approach mounted with the observation that the GABA-B receptor agonist baclofen partially inhibited this reflex. However, baclofen is not suitable for GORD treatment because of central nervous system side-effects. ${ }^{82}$ Hence, analogues of baclofen and alternative TLOSR inhibitors were developed and tested, but side effects and/or limited efficacy eventually led to the discontinuation of these initiatives. ${ }^{60}$

Targeting oesophageal hypersensitivity is another potentially useful strategy in GORD patients with bothersome symptoms despite relatively modest oesophageal acid exposure. ${ }^{58}$ Thus far, attempts to develop TRPV1 antagonists for this purpose have not been successful. ${ }^{83}$ Nevertheless, there are data to suggest that oesophageal sensitivity can be lowered with tricyclic antidepressants and selective serotonin reuptake inhibitors, and this approach is being adopted by many specialists. ${ }^{84} 85$ Controlled data on the efficacy of the approach are awaited.

A relatively new concept pertinent to GORD pathogenesis is that of the acid pocket, the postprandial phenomenon wherein the proximal stomach selectively becomes highly acidic. ${ }^{46}$
Figure $5 \mathrm{pH}$-impedance monitoring allows identification of subgroups of patients with symptoms that are suspected to be caused by reflux. Based on presence or absence of excessive reflux and presence or absence of a temporal association between symptom events and reflux episodes four phenotypes can be identified. The likelihood of a favourable response to antireflux therapy, by inhibition of acid secretion or otherwise, differs among the groups. Patients whose symptoms are not reflux-related (phenotypes 3 and 4) are unlikely to respond to any type of antireflux treatment.

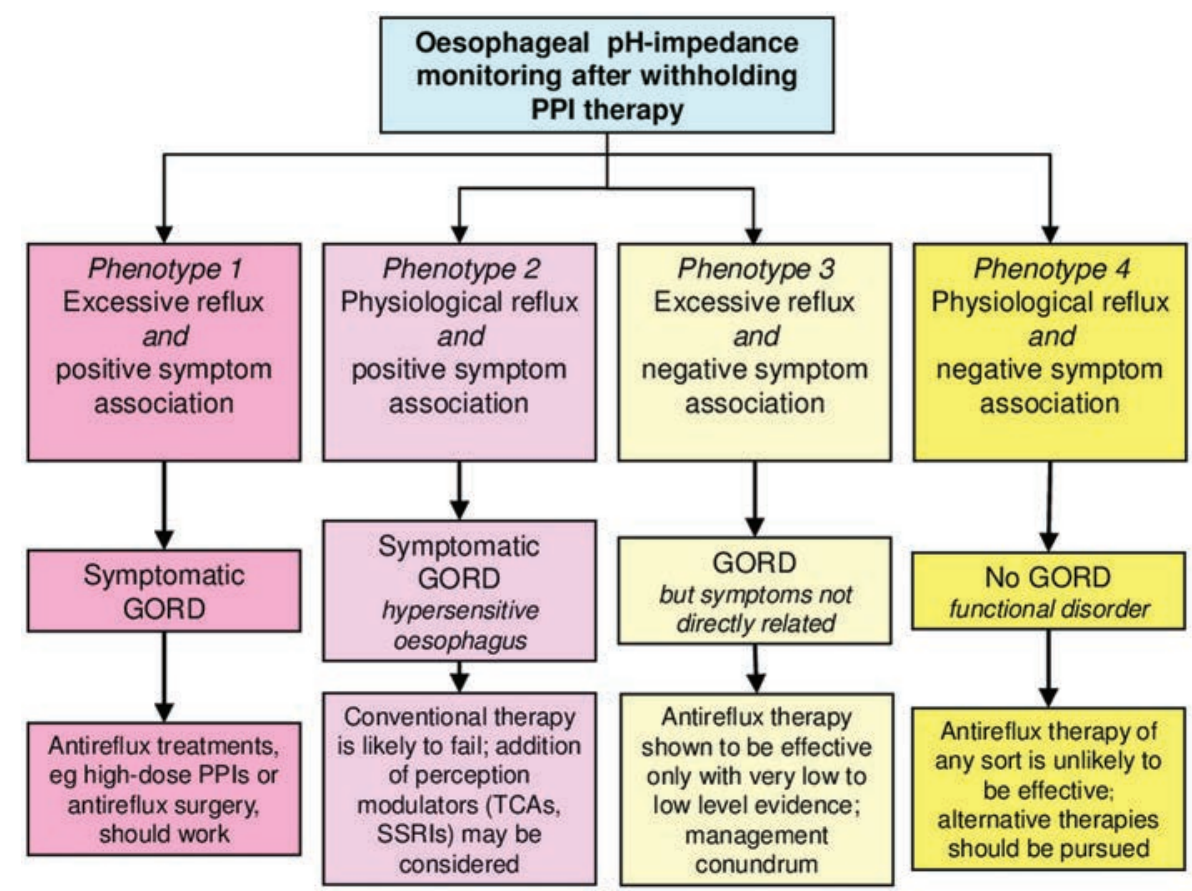


Recently evidence suggests an important role for the acid pocket in the pathogenesis of postprandial reflux and reflux symptoms making this an attractive therapeutic target. One such option is the combination of alginate and antacid. Alginate is a polysaccharide, derived from seaweed, which binds water to form a viscous gum, which floats in the proximal stomach. In a study in 10 symptomatic GORD patients the alginate-antacid combination Gaviscon was found to significantly increase the distance between the pocket and the OGJ and even abolish the pocket in some individuals. ${ }^{86}$ The concept of selective targeting of the acid pocket was also validated in an experiment with radiolabelled gastric acid and Gaviscon in patients with $a \geq 3 \mathrm{~cm}$ hiatus hernia, which showed that Gaviscon colocalised with the newly secreted acid that would have formed the acid pocket. ${ }^{87}$ Three recent studies have demonstrated that Gaviscon reduces acid reflux more than a comparator antacid with equal neutralising capacity. ${ }^{87-89}$ Finally, in a double-blind, placebo-controlled pilot study in 110 symptomatic GORD subjects, greater relief of reflux symptoms was obtained with Gaviscon than with placebo. $^{90}$

\section{Non-medicinal treatment options}

Laparoscopic fundoplication has been shown to effectively reduce the incidence of all types of reflux episodes, acid and non-acid, ${ }^{91}$ and also to provide symptom relief in patients in whom non-acid, or weakly acidic, reflux is an important determinant of symptoms. The 5 -year results of a randomised trial comparing treatment with esomeprazole to laparoscopic Nissen fundoplication indicated no significant overall difference in symptomatic remission rate. However, persisting regurgitation was more prevalent in the PPI group, whereas dysphagia, bloating and flatulence were more common in the fundoplication group. ${ }^{92}$

In the past two decades several endoscopic antireflux procedures were developed that attempted to mimic the effect of surgical fundoplication. Almost invariably, these were marketed before their long-term safety and efficacy were proven. In only two cases, randomised sham-controlled trials were carried out, one with the endoscopic suturing technique (EndoCinch) and one with a device that delivers radiofrequency energy to the OGJ (Stretta). In neither of these studies did active treatment reduce oesophageal acid exposure more effectively than the sham procedure. ${ }^{93}$ 94 Clinical application of these endoscopic antireflux procedures cannot be recommended. More recently, uncontrolled 2-year results suggest efficacy of a transoral plication device (EsophyX) in promoting GORD symptom relief and in alleviating the need to use PPIs for patients without hiatus hernia. ${ }^{95}$ Sham-controlled trials of this device are ongoing.

Two alternative laparoscopic antireflux techniques were also recently introduced. One of these, placement of a flexible band of magnetic beads around the OGJ (LINX system), has been shown to reduce oesophageal acid exposure (from 10.9\% to $3.3 \%$ ), to improve symptoms, and to reduce PPI use. ${ }^{96}$ However, there was no control group in the study, and the follow-up period was 1 year. The other technique, electrical stimulation of the LOS using laparoscopically implanted electrodes, has been reported to increase LOS pressure, to improve GORD symptoms, and to reduce oesophageal acid exposure (from $10.1 \%$ to $3.3 \%$ ) in a small group of esophagitis patients $(n=24)$ without a significant hiatus hernia. ${ }^{97}$ However, there was no sham stimulation arm to the study.

\section{SUMMARY}

Worldwide, the incidence of GORD and its complications (EO, $\mathrm{BO}$ and $\mathrm{OAC}$ ) is increasing, a worrisome observation coinciding with the exponentially increasing problem of obesity. Of great interest is the recently appreciated relationship between central adiposity and GORD, potentially explaining the increased risk in white males to develop complications, including OAC. Mainly driven by progressive insight in the epidemiology and pathophysiology of GORD, the earlier belief that increased gastroesophageal reflux mainly results from one dominant mechanism is now replaced by the acceptance that GORD is a multifactorial disease. As summarised in figure 3, instigating factors such as obesity, age, genetics, pregnancy and trauma may all contribute to mechanical impairment of the OGJ resulting in pathological reflux and accompanying syndromes. Progression of the disease by exacerbating and perpetuating factors such as obesity, neuromuscular dysfunction and oesophageal fibrosis ultimately lead to the development of an overt hiatal hernia. The latter is now accepted as a central player, impacting on most of the mechanisms underlying gastroesophageal reflux (low LOS sphincter pressure, TLOSRs, oesophageal clearance, and acid pocket position), explaining its association with more severe disease and mucosal damage. Since the introduction of PPIs, clinical management of GORD has changed dramatically, shifting the therapeutic challenge from mucosal healing to reduction of PPI-resistant symptoms. In parallel, it became clear that reflux symptoms may result from weakly acidic or non-acid reflux, insight that has triggered the search for new compounds or minimally invasive procedures to reduce all types of reflux. In summary, our view on GORD has evolved enormously compared to that of the past, and without doubt will impact on how to deal with GORD in the future.

Contributors PJK coordinated drafting of the manuscript; all authors contributed to the writing, provided critical revision of the manuscript, and approved the submitted draft. Guarantor of the article: PJK.

Competing interests PJK serves as a paid consultant for AstraZeneca, EndoGastric Solutions, Ironwood Pharmaceuticals, Reckitt Benckiser, and Torax. He receives grant support from the US National Institute of Health (R01 DC00646) and has received grant support from Reckitt Benckiser. HE-S serves as a paid consultant for AstraZeneca and Reckitt Benckiser. He receives grant support from the US National Institute of Health (NCI R01 116845, NIDDK K24-04-107), the Houston VA HSR\&D Center for Innovations in Quality, Effectiveness and Safety (CIn13-413), the Texas Digestive Disease Center NIH DK58338, and has received grant support from Reckitt Benckiser. AJPMS serves as a paid consultant for Reckitt Benckiser and has received financial support for educational meetings from MMS, Given Imaging, Shire, and Movetis. GB is supported by grants from the Research Foundation-Flanders (FWO) (Odysseus programme, G.0905.07) and the agency for Innovation by Science and Technology (IWT), Belgium and has served as a paid consultant for Reckitt Benckiser.

Provenance and peer review Commissioned; externally peer reviewed.

Open Access Open Access This is an Open Access article distributed in accordance with the Creative Commons Attribution Non Commercial (CC BY-NC 3.0) license, which permits others to distribute, remix, adapt, build upon this work noncommercially, and license their derivative works on different terms, provided the original work is properly cited and the use is non-commercial. See: http:// creativecommons.org/licenses/by-nc/3.0/

\section{REFERENCES}

1 Numans ME, Lau J, de Wit NJ, et al. Short-term treatment with proton-pump inhibitors as a test for gastroesophageal reflux disease: a meta-analysis of diagnostic test characteristics. Ann Intern Med 2004;140:518-27.

2 Kahrilas PJ, Shaheen NJ, Vaezi M; AGAI Medical Position Panel on GERD management. AGAI medical position statement: management of gastroesophageal reflux disease. Gastroenterology 2008;135:1383-91.

3 Vakil N, van Zanten SV, Kahrilas P, et al. The Montreal definition and classification of gastro- oesophageal reflux disease: a global evidence-based consensus. Am J Gastroenterol 2006;101:1900-20.

4 Kahrilas PJ, Jonsson A, Denison $\mathrm{H}$, et al. Impact of regurgitation on health-related quality of life in gastro-oesophageal reflux disease before and after short-term potent acid suppression therapy. Gut 2014;63:720-6. 
5 Kahrilas PJ, Boeckxstaens G, Smout AJPM. Management of the patient with incomplete response to PPI therapy. Best Pract Res Clin Gastroenterol 2013:27:401-14.

6 El-Serag HB, Sweet S, Winchester CC, et al. Update on the epidemiology of gastro-oesophageal reflux disease: a systematic review. Gut 2014;63: $871-80$

7 El-Serag HB, Mason AC, Petersen N, et al. Epidemiological differences between adenocarcinoma of the oesophagus and adenocarcinoma of the gastric cardia in the USA. Gut 2002;50:368-72.

8 Thrift AP, Whiteman DC. The incidence of esophageal adenocarcinoma continues to rise: analysis of period and birth cohort effects on recent trends. Ann Oncol 2012:23:3155-62

9 Cook MB, Chow WH, Devesa SS. Oesophageal cancer incidence in the United States by race, sex, and histologic type, 1977-2005. Br J Cancer 2009;101: 855-9.

10 Kramer JR, Fischbach LA, Richardson P, et al. Waist-to-hip ratio, but not body mass index, is associated with an increased risk of Barrett's esophagus in white men. Clin Gastroenterol Hepatol 2013;11:373-81.e1.

11 Singh S, Sharma AN, Murad MH, et al. Central adiposity is associated with increased risk of esophageal inflammation, metaplasia, and adenocarcinoma: a systematic review and meta-analysis. Clin Gastroenterol Hepatol 2013;11:1399-412.e7.

12 Lagergren J, Mattsson F, Nyrén 0. Gastroesophageal reflux does not alter effects of body mass index on risk of esophageal adenocarcinoma. Clin Gastroenterol Hepatol 2014:12:45-51.

13 El-Serag H. Role of obesity in GORD-related disorders. Gut 2008; 57:281-4

14 El-Serag HB, Hashmi A, Garcia J, et al. Visceral abdominal obesity measured by CT scan is associated with an increased risk of Barrett's oesophagus: a case-control study. Gut 2014;63:220-9.

15 Duggan C, Onstad L, Hardikar S, et al. Association between markers of obesity and progression from Barrett's esophagus to esophageal adenocarcinoma. Clin Gastroenterol Hepatol 2013;11:934-43.

16 Liska D, Dufour $\mathrm{S}$, Zern TL, et al. Interethnic differences in muscle, liver, and abdominal fat partitioning in obese adolescents. PLOS ONE 2007;2 e569.

17 Erichsen R, Robertson D, Farkas DK, et al. Erosive reflux disease increases risk for esophageal adenocarcinoma, compared with nonerosive reflux. Clin Gastroenterol Hepatol 2012;10:475-80.e1.

18 Nelson SP, Kothari S, Wu EQ, et al. Pediatric gastroesophageal reflux disease and acid-related conditions: trends in incidence of diagnosis and acid suppression therapy. J Med Econ 2009;12:348-55.

19 El-Serag HB, Gilger M, Carter J, et al. Childhood GERD is a risk factor for GERD in adolescents and young adults. Am J Gastroenterol 2004;99:806-12.

20 El-Serag HB, Richardson P, Pilgrim P, et al. Determinants of gastroesophageal reflux disease in adults with a history of childhood gastroesophageal reflux disease. Clin Gastroenterol Hepatol 2007;5:696-701.

21 Thrift AP, Kramer JR, Qureshi Z, et al. Age at onset of GERD symptoms predicts risk of Barrett's esophagus. Am J Gastroenterol 2013;108:915-22.

22 Singh S, Garg SK, Singh PP, et al. Acid-suppressive medications and risk of oesophageal adenocarcinoma in patients with Barrett's oesophagus: a systematic review and meta-analysis. Gut 2014 63:1229-37

23 Fischbach LA, Nordenstedt $H$, Kramer JR, et al. The association between Barrett's esophagus and Helicobacter pylori infection: a meta-analysis. Helicobacter 2012:17:163-75.

24 Islami F, Kamangar F. Helicobacter pylori and esophageal cancer risk: a meta-analysis. Cancer Prev Res (Phila) 2008:1:329-38.

25 Rubenstein JH, Inadomi JM, Scheiman J, et al. Association between Helicobacter pylori and Barrett's esophagus, erosive esophagitis, and gastroesophageal reflux symptoms. Clin Gastroenterol Hepatol 2014;12:239-45.

26 El-Serag HB, Sonnenberg A, Jamal MM, et al. Corpus gastritis is protective against reflux oesophagitis. Gut 1999:45:181-5.

27 Fischbach L, Graham DY, Kramer JR, et al. Association between Helicobacter pylori and Barrett's esophagus: a case-control study. Am J Gastroenterol Published Online First: 14 Jan 2014. doi:10.1038/ajg.2013.443

28 West T. A treatise on pyrosis idiopathica, or water-brash, as contrasted with certain forms of indigestion and of organic lesions of the abdominal organs; together with the remedies dietetic and medicinal. Longman, Orme, Brown, Green, and Longmans. London, 1841

29 Winkelstein A. peptic esophagitis. JAMA 1935;104:906-9.

30 Stylopoulos N, Rattner SW. The history of hiatal hernia surgery from Bowditch to laparoscopy. Ann Surg 2005;241:185-93.

31 Cohen S, Harris LD. Does hiatus hernia affect competence of the gastroesophagea sphincter? N Engl J Med 1971;284:1053-6.

32 Mittal RK, Rochester DF, McCallum RW. Electrical and mechanical activity in the human lower esophageal sphincter during diaphragmatic contraction. J Clin Invest 1988:81:1182-9.
33 Sloan S, Rademaker AW, Kahrilas PJ. Determinants of gastroesophageal junction incompetence: hiatal hernia, lower esophageal sphincter, or both? Ann Intern Med 1992:117:977-82

34 Dent J, Dodds WJ, Friedman RH, et al. Mechanism of gastroesophageal reflux in recumbent asymptomatic human subjects. J Clin Invest 1980;

65:256-67.

35 Mittal RK, Holloway RH, Penagini R, et al. Transient lower esophageal sphincter relaxation. Gastroenterology 1995;109:601-10.

36 Mittal RK, Lange RC, McCallum RW. Identification and mechanism of delayed esophageal acid clearance in subjects with hiatus hernia. Gastroenterology 1987:92:130-5

37 Sloan S, Kahrilas PJ. Impairment of esophageal emptying with hiatal hernia. Gastroenterology 1991;100:596-605.

38 Jones MP, Sloan SS, Jovanovic B, et al. Impaired egress rather than increased access: an important independent predictor of erosive esophagitis. Neurogastroenterol Mot 2002;14:625-31.

39 Pandolfino JE, Shi G, Curry J, et al. Esophagogastric junction distensibility: a factor contributing to sphincter incompetence. Am J Physiol Gastrointest Liver Physiol 2002:282:G1052-8

40 Pandolfino JE, Shi G, Trueworthy B, et al. Esophagogastric junction opening during relaxation distinguishes nonhernia reflux patients, hernia patients, and normal subjects. Gastroenterology 2003;125:1018-24.

41 Woodland P, Sifrim D. The refluxate: the impact of its magnitude, composition and distribution. Best Pract Res Clin Gastroenterol 2010;24:861-71.

42 Rohof WO, Bennink RJ, de Jonge $\mathrm{H}$, et al. Increased proximal reflux in a hypersensitive esophagus might explain symptoms resistant to proton pump inhibitors in patients with gastroesophageal reflux disease. Clin Gastroenterol Hepatol Published Online First: 1 Nov 2013. doi:10.1016/j.cgh.2013.10.026

43 Cannon WB. The movements of the stomach, studied by means of the röntgen rays. J Boston Soc Med Sci 1898:2:59-66.

44 Fletcher J, Wirz A, Henry E, et al. Studies of acid exposure immediately above the gastro-esophageal squamocolumnar junction: evidence of short segment reflux. Gut 2004;53:168-73.

45 Fletcher J, Wirz A, Young J, et al. Unbuffered highly acidic gastric juice exists at the gastroesophageal junction after a meal. Gastroenterology 2001; 121:775-83.

46 Beaumont $\mathrm{H}$, Bennink RJ, de Jong J, et al. The position of the acid pocket as a major risk factor for acidic reflux in healthy subjects and patients with GERD. Gut 2010:59:441-51.

47 Kahrilas PJ, McColl K, Fox M, et al. The acid pocket: a target for treatment in reflux disease. Am J Gastroenterol 2013;108:1058-64.

48 Pandolfino JE, Zhang QG, Ghosh SK, et al. Transient lower esophageal sphincter relaxations and reflux: mechanistic analysis using concurrent fluoroscopy and high-resolution manometry. Gastroenterology 2006;131:1725-33.

49 Mittal RK. Longitudinal muscle of the esophagus: its role in esophageal health and disease. Curr Opin Gastroenterol 2013;29:421-30.

50 Kahrilas PJ, Lin S, Chen J, et al. The effect of hiatus hernia on gastro-esophageal junction pressure. Gut 1999;44:476-82.

51 Kahrilas PJ, Shi G, Manka M, et al. Increased frequency of transient lower esophageal sphincter relaxation induced by gastric distention in reflux patients with hiatal hernia. Gastroenterology 2000;118:688-95.

52 van Herwaarden MA, Samsom M, Smout AJ. Excess gastroesophageal reflux in patients with hiatus hernia is caused by mechanisms other than transient LES relaxations. Gastroenterology 2000;119:1439-46.

53 Pandolfino JE, Zhang Q, Ghosh SK, et al. Acidity surrounding the squamocolumnar junction in GERD patients: "acid pocket" versus "acid film". Am J Gastroenterol 2007; 102:2633-41.

54 Bredenoord AJ, Weusten BL, Timmer R, et al. Intermittent spatial separation of diaphragm and lower esophageal sphincter favors acidic and weakly acidic reflux. Gastroenterology 2006;130:334-40.

55 Robertson EV, Derakhshan $\mathrm{MH}$, Wirz AA, et al. Central obesity in asymptomatic volunteers is associated with increased intrasphincteric acid reflux and lengthening of the cardiac mucosa. Gastroenterology 2013;145:730-9.

56 Lee YY, Wirz AA, Whiting JG, et al. Waist belt and central obesity cause partial hiatus hernia and short-segment acid reflux in asymptomatic volunteers. Gut 2014;63:1053-60.

57 Pandolfino JE, El-Serag HB, Zhang Q, et al. Obesity: a challenge to esophagogastric junction integrity. Gastroenterology 2006;130:639-49.

58 Knowles $\mathrm{CH}$, Aziz Q. Visceral hypersensitivity in non-erosive reflux disease. Gut 2008:57:674-83.

59 Kahrilas PJ, Smith JA, Dicpinigaitis PV. A causal relationship between cough and gastroesophageal reflux disease (GERD) has been established: a pro/con debate. Lung 2014;192:39-46.

60 Kahrilas PJ, Boeckxstaens G. Failure of reflux inhibitors in clinical trials: bad drugs or wrong patients? Gut 2012;61:1501-9.

61 Kahrilas PJ, Howden CW, Hughes N. Response of regurgitation to proton pump inhibitor therapy in clinical trials of gastroesophageal reflux disease. Am J Gastroenterol 2011:106:1419-25. 
62 Kahrilas PJ, Jonsson A, Denison $\mathrm{H}_{\text {, et }}$ al. Regurgitation is less responsive to acid suppression than heartburn in patients with gastroesophageal reflux disease. Clin Gastroenterol Hepatol 2012;10:612-19.

63 Kahrilas PJ, Hughes N, Howden CW. Response of unexplained chest pain to proton pump inhibitor treatment in patients with and without objective evidence of gastro-oesophageal reflux disease. Gut 2011;60:1473-8.

64 Kahrilas PJ, Howden CW, Hughes N, et al. Response of chronic cough to acid-suppressive therapy in patients with gastroesophageal reflux disease. Chest 2013;143:605-12.

65 Vaezi MF, Richter JE, Stasney CR, et al. Treatment of chronic posterior laryngitis with esomeprazole. Laryngoscope 2006;116:254-60.

66 The American Lung Association Asthma Clinical Research Center. Efficacy of esomeprazole for treatment of poorly controlled asthma. N Engl J Med 2009;360:1487-99.

67 Bredenoord AJ, Weusten BL, Curvers WL, et al. Determinants of perception of heartburn and regurgitation. Gut 2006;55:313-18.

68 Jacobson BC, Somers SC, Fuchs CS, et al. Body-mass index and symptoms of gastroesophageal reflux in women. N Engl J Med 2006;354:2340-8.

69 Singh M, Lee J, Gupta N, et al. Weight loss can lead to resolution of gastroesophageal reflux disease symptoms: a prospective intervention trial. Obesity (Silver Spring) 2013;21:284-90.

70 de Jong JR, Besselink MG, van Ramshorst B, et al. Effects of adjustable gastric banding on gastroesophageal reflux and esophageal motility: a systematic review. Obes Rev 2010;11:297-305.

71 Miguel GP, Azevedo JL, de Souza PH, et al. Erosive esophagitis after bariatric surgery: banded vertical gastrectomy versus banded Roux-en-Y gastric bypass. Obes Surg 2011;21:167-72.

72 Braghetto I, Korn 0, Csendes A, et al. Laparoscopic treatment of obese patients with gastroesophageal reflux disease and Barrett's esophagus: a prospective study. Obes Surg 2012:22:764-72.

73 Hirschowitz BI. A critical analysis, with appropriate controls, of gastric acid and pepsin secretion in clinical esophagitis. Gastroenterology 1991;101:1149-58.

74 Bardhan KD, Muller-Lissner S, Bigard MA, et al. Symptomatic gastro-oesophageal reflux disease: double blind controlled study of intermittent treatment with omeprazole or ranitidine. The European Study Group. BMJ 1999:318:502-7.

75 Miner P Jr, Katz PO, Chen Y, et al. Gastric acid control with esomeprazole, lansoprazole, omeprazole, pantoprazole, and rabeprazole: a five-way crossover study. Am J Gastroenterol 2003;98:2616-20.

76 Fackler WK, Ours TM, Vaezi MF, et al. Long-term effect of H2RA therapy on nocturnal gastric acid breakthrough. Gastroenterology 2002;122:625-32.

77 Sifrim D, Holloway R, Silny J, et al. Acid, nonacid, and gas reflux in patients with gastroesophageal reflux disease during ambulatory 24-hour $\mathrm{pH}$-impedance recordings. Gastroenterology 2001;120:1588-98.

78 Hemmink GJ, Bredenoord AJ, Weusten BL, et al. Esophageal pH-impedance monitoring in patients with therapy-resistant reflux symptoms: 'on' or 'off' proton pump inhibitor? Am J Gastroenterol 2008:103:2446-53.

79 Chander B, Hanley-Williams N, Deng Y, et al. 24 Versus 48-hour Bravo pH monitoring. J Clin Gastroenterol 2012;46:197-200.

80 Leite LP, Johnston BT, Just RJ, et al. Persistent acid secretion during omeprazole therapy: a study of gastric acid profiles in patients demonstrating failure of omeprazole therapy. Am J Gastroenterol 1996;91:1527-31.

81 Van Soest EM, Siersema PD, Dieleman JP, et al. Persistence and adherence to proton pump inhibitors in daily clinical practice. Aliment Pharmacol Ther 2006;24:377-85
82 Lidums I, Lehmann $\mathrm{A}$, Checklin $\mathrm{H}$, et al. Control of transient lower esophageal sphincter relaxations and reflux by the $\mathrm{GABA}(\mathrm{B})$ agonist baclofen in normal subjects. Gastroenterology 2000;118:7-13.

83 Krarup AL, Ny L, Gunnarsson J, et al. Randomized clinical trial: inhibition of the TRPV1 system in patients with nonerosive gastroesophageal reflux disease and a partial response to PPI treatment is not associated with analgesia to esophageal experimental pain. Scand J Gastroenterol 2013;48:274-84.

84 Broekaert D, Fischler B, Sifrim D, et al. Influence of citalopram, a selective serotonin reuptake inhibitor, on oesophageal hypersensitivity: a double-blind, placebo-controlled study. Aliment Pharmacol Ther 2006:23:365-70.

85 Viazis N, Karamanolis G, Vienna E, et al. Selective-serotonin reuptake inhibitors for the treatment of hypersensitive esophagus. Therap Adv Gastroenterol 2011;4:295-300

86 Kwiatek MA, Roman S, Fareeduddin A, et al. An alginate-antacid formulation (Gaviscon Double Action Liquid) can eliminate or displace the postprandial 'acid pocket' in symptomatic GERD patients. Aliment Pharmacol Ther 2011;34: $59-66$

87 Rohof WO, Bennink RJ, Smout AJ, et al. An alginate-antacid formulation localizes to the acid pocket to reduce acid reflux in patients with gastroesophageal reflux disease. Clin Gastroenterol Hepatol 2013;11:1585-91.

88 Chen J, de Ruigh A, Pandolfino JE, et al. Gaviscon double action (antacid + alginate) is more effective than antacid alone in controlling post-prandial acid reflux in GERD patients; a double-blind crossover study. UEGW, 2013. http://www. e-learning.ueg.eu/documents-view.html?no_cache $=1$ \&eprs $\% 5 B r \% 5 D=20876$

89 Sweis R, Kaufman E, Anggiansah A, et al. Post-prandial reflux suppression by a raft-forming alginate (Gaviscon Advance) compared to a simple antacid documented by magnetic resonance imaging and $\mathrm{pH}$-impedance monitoring: mechanistic assessment in healthy volunteers and randomised, controlled, double-blind study in reflux patients. Aliment Pharmacol Ther 2013;37:1093-102.

90 Thomas E, Wade A, Crawford G, et al. Randomised clinical trial: relief of upper gastrointestinal symptoms by an acid pocket-targeting alginate-antacid (Gaviscon Double Action) — a double-blind, placebo-controlled, pilot study in gastro-oesophageal reflux disease. Aliment Pharmacol Ther Published Online First: 28 Jan 2014. doi:10.1111/apt.12640

91 Bredenoord AJ, Draaisma WA, Weusten BL, et al. Mechanisms of acid, weakly acidic and gas reflux after anti-reflux surgery. Gut 2008:57:161-6.

92 Galmiche JP, Hatlebakk J, Attwood S, et al. Laparoscopic antireflux surgery vs esomeprazole treatment for chronic GERD: the LOTUS randomized clinical trial. JAMA 2011:305:1969-77.

93 Schwartz MP, Wellink H, Gooszen HG, et al. Endoscopic gastroplication for the treatment of gastro-oesophageal reflux disease: a randomised, sham-controlled trial. Gut 2007;56:20-8.

94 Arts J, Bisschops R, Blondeau K, et al. A double-blind sham-controlled study of the effect of radiofrequency energy on symptoms and distensibility of the gastro-esophageal junction in GERD. Am J Gastroenterol 2012;107:222-30.

95 Cadière GB, Van Sante N, Graves JE, et al. Two-year results of a feasibility study on antireflux transoral incisionless fundoplication using EsophyX. Surg Endosc 2009;23:957-64

96 Ganz RA, Peters JH, Horgan S, et al. Esophageal sphincter device for gastroesophageal reflux disease. N Engl J Med 2013;368:719-27.

97 Rodríguez L, Rodriguez P, Gómez B, et al. Long-term results of electrical stimulation of the lower esophageal sphincter for the treatment of gastroesophageal reflux disease. Endoscopy 2013;45:595-604. 